\title{
EULAR/PReS standards and recommendations for the transitional care of young people with juvenile-onset rheumatic diseases
}

Helen E Foster, ${ }_{1}^{1}$ Kirsten Minden, ${ }^{2,3}$ Daniel Clemente, ${ }^{4}$ Leticia Leon, ${ }^{5,6}$

Janet E McDonagh, ${ }^{7}$ Sylvia Kamphuis, ${ }^{8}$ Karin Berggren, ${ }^{9}$ Philomine van Pelt, ${ }^{10}$ Carine Wouters, ${ }^{11}$ Jennifer Waite-Jones, ${ }^{12}$ Rachel Tattersall, ${ }^{13}$ Ruth Wyllie, ${ }^{14}$ Simon R Stones, ${ }^{15}$ Alberto Martini, ${ }^{16}$ Tamas Constantin, ${ }^{17}$ Susanne Schalm, ${ }^{18}$ Berna Fidanci, ${ }^{19}$ Burak Erer, $^{20}$ Erkan Dermikaya, ${ }^{21}$ Seza Ozen, ${ }^{22}$ Loreto Carmona ${ }^{23}$

\begin{abstract}
Handling editor Tore K Kvien
- Additional material is published online only. To view please visit the journal online (http://dx.doi.org/10.1136/ annrheumdis-2016-210112).
\end{abstract}

For numbered affiliations see end of article.

Correspondence to Dr Leticia Leon, Instituto de Investigación Sanitaria del Hospital Clínico San Carlos (IDISSC), Hospital Clínico San Carlos, Martin Lagos s/n, Madrid 28040, Spain; lleon.hcsc@salud.madrid.org

HEF and KM contributed equally.

Received 23 June 2016 Revised 11 October 2016 Accepted 16 October 2016 Published Online First 1 November 2016

\section{CrossMark}

$$
\begin{aligned}
& \text { To cite: Foster HE, } \\
& \text { Minden K, Clemente D, } \\
& \text { et al. Ann Rheum Dis } \\
& \text { 2017;76:639-646. }
\end{aligned}
$$

\section{ABSTRACT}

To develop standards and recommendations for transitional care for young people (YP) with juvenileonset rheumatic and musculoskeletal diseases (jRMD). The consensus process involved the following: (1) establishing an international expert panel to include patients and representatives from multidisciplinary teams in adult and paediatric rheumatology; (2) a systematic review of published models of transitional care in jRMDs, potential standards and recommendations, strategies for implementation and tools to evaluate services and outcomes; (3) setting the framework, developing the process map and generating a first draft of standards and recommendations; (4) further iteration of recommendations; (5) establishing consensus recommendations with Delphi methodology and (6) establishing standards and quality indicators. The final consensus derived 12 specific recommendations for YP with jRMD focused on transitional care. These included: high-quality, multidisciplinary care starting in early adolescence; the integral role of a transition coordinator; transition policies and protocols; efficient communications; transfer documentation; an open electronic-based platform to access resources; appropriate training for paediatric and adult healthcare teams; secure funding to continue treatments and services into adult rheumatology and the need for increased evidence to inform best practice. These consensus-based recommendations inform strategies to reach optimal outcomes in transitional care for YP with jRMD based on available evidence and expert opinion. They need to be implemented in the context of individual countries, healthcare systems and regulatory frameworks.

\section{INTRODUCTION}

Transitional care, as defined by the Society for Adolescent Medicine, is "the purposeful, planned movement of adolescents and young adults with chronic physical and medical conditions from childcentred to adult-oriented healthcare systems". ${ }^{1}$ Transition focuses on the administrative event of transfer of care between paediatric and adult providers; transition encompasses the process by which young people (YP) acquire skills and access resources to ensure that their physical, psychosocial, educational and vocational needs are met during transition to adulthood. ${ }^{2}$ Adolescence and young adulthood reflect an important and unique developmental period for all YP who need education, support, guidance and planning to prepare them to be appropriately responsible and accountable for their own health and well-being as adults. ${ }^{3}$ The same principle applies to YP with chronic illnesses (including juvenile-onset rheumatic and musculoskeletal diseases (jRMDs)), who need to acquire additional skills to independently manage their chronic illness. The case of need for transition is well described and transitional care aims to provide support and guidance so that $\mathrm{YP}$ can acquire the necessary skills and knowledge required to be independent, empowered and responsible adults. $^{4-7}$

The course of $\mathrm{jRMDs}$ often continues into adulthood; according to population-based inception cohort studies, approximately half of YP with jRMDs enter adulthood with active disease, or develop flares of disease as adults. Many YP require ongoing and often long-term treatment with complex immunosuppressive regimes. ${ }^{8-10}$ Diseaserelated sequelae are still observed, although with modern approaches to management, many YP are transferring to adult care in clinical remission albeit on medication. ${ }^{11-13}$ All YP with jRMDs are, in principle, at significant risk of disability, early morbidity and limitations in participation later in life. ${ }^{14} 15$ These YP need continuous and developmentally appropriate care during and beyond adolescence to ensure optimal functioning in adulthood. However, the literature informs us that currently up to half of the YP do not make a successful transfer to adult rheumatology and are therefore at particular risk of unfavourable outcomes. $^{16-18}$

The importance of transitional care in YP with jRMD has been increasingly acknowledged. ${ }^{19} \quad 20$ There is evidence regarding 'best practice' for transitional care, with emphasis on a holistic 'life course' approach to care. ${ }^{21-23}$ Several healthcare institutions, specialties and disease-specific subgroups have developed and implemented transition programmes. ${ }^{24-34}$ However, there is lack of clarity regarding the impact of transition programme on outcomes, and indeed, variance in what the outcomes should be. ${ }^{35-40}$ A first consensus-based proposal regarding outcome indicators for successful healthcare transition was recently made by an 
international group of interdisciplinary healthcare professionals, patients and their families. ${ }^{41}$ With rheumatology, there are significant gaps in current delivery of transition services and these include the unmet training needs for healthcare professionals in adolescent health and transitional care (resulting in lack of understanding and appreciation of the needs of YP), lack of transition readiness of YP (and/or of their parents/carers) and lack of robust quality indicators or cost-effective strategies. $^{2} 3642-48$

Despite the limitations of the existing programmes, the gaps in knowledge and the paucity of resources, there is nonetheless commitment within the rheumatology communities (both adult and paediatric), to improve existing transitional care services. There is a strong desire for rheumatology-specific guidelines for transition $^{48}$ and for these to be implemented across paediatric, adolescent and adult rheumatology healthcare settings.

\section{Objectives, scope, users and overarching principles}

The objective of the present initiative was to develop recommendations and standards for transitional care for YP with jRMDs, spanning ages from early adolescence (defined as 10-13 years), mid adolescence (14-16 years), late adolescence (17-19 years) to young adulthood (20-24 years). ${ }^{49} 50$ These recommendations and standards are to be used to guide service development, benchmark the quality of transition services and be used by patient organisations to enhance patient expectations of care. We acknowledge that their implementation into clinical practice will be challenging and likely to be facilitated by stratification into 'essential' and 'ideal' components-essential defined as the minimum standards below which care would be deemed unacceptable and ideal being the standard that is regarded as excellent 'optimal' care.

The purpose of these recommendations and standards is to increase the profile of transition, optimise delivery of transitional care and improve patient experience within rheumatology across European countries. Specifically, the objectives are:

- to ensure youth friendly and developmentally appropriate care,

- to improve physical, psychological, social, vocational and illness-related outcomes of YP with jRMDs,

- to facilitate continuity of care within adult rheumatology,

- to promote evidence-based practice in transitional care,

- to facilitate clinical networks of healthcare professionals (paediatric and adult), who are engaged, interested and trained in the care of YP.

The scope of these recommendations and standards refers to all persons involved in the care of YP with jRMDs that continue into adulthood including, but not restricted to, those in box 1.

Although these recommendations and standards are related to the specific needs of YP with jRMDs, our expert panel endorse the American Academy of Pediatrics, the American Academy of Family Physicians and the American College of Physicians-American Society of Internal Medicine consensus statement on healthcare transitions for YP with special healthcare needs, ${ }^{51} 52$ position papers of the Society for Adolescent Medicine, ${ }^{1}$ 53-55 the Canadian Paediatric Society, ${ }^{56}$ the Royal Australasian College of Physicians ${ }^{57}$ and the WHO definition of adolescent-friendly health services. ${ }^{58} 59$ In addition, we emphasise key components integral to these recommendations and standards, namely the importance of a YP focus, multidisciplinary approach with equity of access, quality of care and flexibility; the latter acknowledging both the heterogeneity of YP development and potential impact of chronic illness.
Box 1 Individuals to whom these recommendations may prove useful

Adult and paediatric rheumatologists

Other healthcare professionals:

- nurses

- physiotherapists

- occupational therapists

- social workers

- psychologists

- youth workers

- primary care and other specialists (eg, ophthalmology, dermatology, nephrology, orthopaedics) involved in share care and clinical networks

General practitioners and healthcare professionals working in primary care

Young people with rheumatic and musculoskeletal disease (RMD) and other multisystem disease, their families and peers Professional groups or societies working with young people with RMDs

Academics involved in adolescent and young adult health research

In addition, these standards and recommendations are intended

to be useful to the remit of

- educational and vocational services

- employers and careers advisory services

- charities and support organisations

- funders of clinical services

- health policy makers

- research funding bodies

- organisers of disease and/or drug registers, and cohort studies

\section{METHODS}

The consensus process underwent the following stages: (1) establishing an international expert panel to include patients and representatives from multidisciplinary teams (MDTs) in adult and paediatric rheumatology; (2) a systematic literature review; (3) setting the framework, developing the process map and generating a first draft of standards and recommendations; (4) further iteration of recommendations; (5) developing consensus recommendations with Delphi methodology and (6) establishing standards and quality indicators, as suggested by the European League Against Rheumatism (EULAR) Standard Operating Procedures. ${ }^{60}$

The project convenors (HF, KM, LC) liaised to appoint clinical fellows (DC, LL) to work on the project. They then convened an expert multidisciplinary panel from adult and paediatric rheumatology across Europe (doctors and allied health professionals with interest in transitional care) and patient representatives (YP with jRMDs invited from existing patient groups). The aim was for the panel to reflect the diversity of Europe (namely geography, healthcare systems and cultures).

A systematic literature review of existing models of transitional care in jRMD was performed, with emphasis on potential recommendations, standards, strategies for implementation and tools to evaluate services and outcomes. ${ }^{35}$

The first 'face-to-face' meeting of the expert panel discussed results of the systematic review and agreed the following:

(i) purpose of the project, timelines, roles and planned outputs; 
(ii) the 'process map' of transitional care using MindManager software;

(iii) a draft proposal of recommendations and standards relating to different elements of the process map; the proposed list was circulated after the meeting by email to the expert group and further feedback requested.

A second 'face-to-face' meeting further refined the recommendations and standards based on feedback from the group. Appropriate quality indicators were also suggested for each recommendation and standard.

The recommendations and standards were then listed as statements. A wider audience of a total of 195 adult and paediatric rheumatology clinicians (doctors and allied health professionals) were then invited to take part in an e-survey and give opinion of their level of agreement with each statement. The e-survey was disseminated through email lists held by professional groups (such as Paediatric Rheumatology European Society (PReS), EULAR and rheumatology societies in different countries). All responses were anonymised. Participants were asked for their level of agreement with each statement (using a 10-point Likert scale, with $0=$ no agreement through to $10=$ total agreement) and a ranking exercise to identify 'minimal' and 'optimal' standards for each recommendation. The target number of respondents for the e-survey was 100 and the level of agreement set at $80 \%$ for acceptance (lower levels were to be then discussed by the expert panel, with further iterations of the statements proposed and then a second e-survey, if needed, to be disseminated). Once agreement was reached, the methodologist (LC), together with the clinical fellows (DC, LL), graded the level of evidence for each recommendation based on the Oxford Levels of Evidence, 2011 (available at http://www.cebm.net/index.aspx? $\mathrm{o}=5653$ ) and assigned relevant quality indicators where appropriate.

\section{RESULTS}

\section{The recommendations and standards}

The recommendations and standards, reported as 'minimal/ essential' and 'ideal/optimal' levels of care and quality indicators are listed below; they are also presented in table format with the level of evidence and agreement reached (table 1).
(1) YP with jRMDs should have access to high-quality, co-ordinated transitional care, delivered through partnership with healthcare professionals, YP and their families, to address their needs on an individual basis.

High-quality care means holistic care (which covers medical, psychosocial, educational and vocational aspects; see box 2) with a multidisciplinary approach and is based upon regular assessments of the disease status in the context of developmental stage, life events and personal aspirations of YP. This care needs to be 'future-focussed', albeit not limited to young adulthood, in order to ensure optimal well-being. ${ }^{19} 23$

Ideal: provision of a broad set of healthcare services led by providers who have specialist knowledge about jRMDs and adolescent health; essential: care providers who refer to other agencies and services who can appropriately assist with transition issues.

(2) The transition process should start as early as possible; in early adolescence or directly after the diagnosis in adolescent-onset disease.

Specifically for childhood-onset diseases, the transition process should start by early adolescence (11 years) (ideal) or 14 years at the latest (essential) in order to allow the development of the necessary self-care skills and optimise educational and vocational outcomes. ${ }^{63}{ }^{64}$ For YP who are diagnosed over the age of 14 years, the transition process should start at the time of diagnosis with the skills and support for transition built-up over time. The transition process or joint care programmes should enclose early adulthood, because young adults continue to have difficulties making effective linkages with adult care. Brain development continues and risk behaviours remain and may increase in the third decade, which have to be considered by proactive and preventive care. ${ }^{65}$

(3) There must be 'direct' communication between the key participants (and as a minimum, to include the YP, parent/carer and a member of each of the paediatric and adult rheumatologist teams) during the process of transition. Before and after the actual transfer, there should be 'direct' contacts between paediatric and adult rheumatologist teams.

A network of adult rheumatologists interested, engaged with and trained in adolescent rheumatology, must be identified and known to the paediatric rheumatology team. The network

\section{Table 1 Recommendations, standards and proposed quality indicators on transitional care for young persons with RMD}

\begin{tabular}{|c|c|c|c|}
\hline Recommendations & LOE & GR & MA \\
\hline $\begin{array}{l}\text { 1. YP with RMD should have access to high-quality, co-ordinated transitional care, delivered through partnership with healthcare professionals, YP and their } \\
\text { families, to address needs on an individual basis }\end{array}$ & 5 & D & 9.6 \\
\hline 2. The transition process should start as early as possible; in early adolescence or directly after the diagnosis in adolescent-onset disease & $2 b$ & B & 8.3 \\
\hline $\begin{array}{l}\text { 3. There must be 'direct' communication between the key participants (and as a minimum, to include the YP, parent/carer, and a member each of the } \\
\text { paediatric and adult rheumatologist teams) during the process of transition. Before and after the actual transfer, there should be 'direct' contacts } \\
\text { between paediatric and adult rheumatologist teams }\end{array}$ & 5 & D & 9.3 \\
\hline 4. Individual transition processes and progress should be carefully documented in the medical records and planned with YP and their families & 5 & D & 9.2 \\
\hline 5. Every rheumatology service and clinical network—paediatric and adult-must have a written, agreed and regularly updated transition policy & 5 & D & 8.9 \\
\hline $\begin{array}{l}\text { 6. There should be clear written description of the MDT involved in transitional care, locally and in the clinical network. The MDT should include a } \\
\text { designated transition co-ordinator }\end{array}$ & 5 & $\mathrm{D}$ & 8.7 \\
\hline 7. Transition services must be YP focused, be developmentally appropriate and address the complexity of YP development & 5 & $\mathrm{D}$ & 9.4 \\
\hline 8. There must be a transfer document & 5 & $\mathrm{D}$ & 9.4 \\
\hline $\begin{array}{l}\text { 9. Healthcare teams involved in transition and adolescent-young adult care must have appropriate training in generic adolescent care and childhood-onset } \\
\text { RMD }\end{array}$ & 5 & $\mathrm{D}$ & 9.5 \\
\hline 10. There must be secure funding for dedicated resources to provide uninterrupted clinical care and transition services for YP entering adult care & 5 & D & 9.4 \\
\hline 11. There must be a freely accessible electronic-based platform to host the recommendations, standards and resources for transitional care & 5 & D & 9.4 \\
\hline 2. Increased evidence-based knowledge a & 5 & $\mathrm{D}$ & \\
\hline
\end{tabular}

GR, grade of recommendation; LOE, level of evidence; MA, mean agreement (0-10); MDT, multidisciplinary team; YP, young people. 


\section{Box 2 Aspects considered as part of holistic care}

Medical aspects:

- identification of medical needs, addressing any issues

- ensuring continuity of provision of high-quality care

- providing generic and disease-specific information

- health promotion, anticipatory guidance

health behaviour (eg, health literacy, experimentation and risk behaviour), negotiating most appropriate ways to ensure adherence to treatment

knowledge and skills in areas listed above

Psychosocial aspects:

- identifying individual needs, risk and protective factors (eg, Home, Education, Activities, Drugs, Sex, Suicide (HEADSS)) ${ }^{61} 62$

- providing support or referring young people to specific agencies

- ensuring a social life that is equivalent to those of peers

- ensuring support to cope with disease/treatment

- providing advice and/or additional sources of support

- promoting skills in assertiveness, resilience, self-care, self-determination and self-advocacy

Educational and vocational aspects:

- addressing future career prospects

- developing skills in disclosure

- support in preparing for work readiness

- informing about where to get information (recommend: career advisors, appropriate agencies, charity websites)

- addressing work experience and encouraging young people to gain relevant experience

- offer appropriate information, support and advice (support groups, volunteer services)

- liaisons with educational institutions

- informing about rights and obligations, benefits and opportunities to adapt working (place, time)

should work within agreed pathways to facilitate transition and expedite early, active planning of transition. Ideally, there should be a combined meeting between the young person and his or her family, the paediatric and adult healthcare provider. $^{66-68}$ As a minimum, there should be at least two 'direct' contacts by telephone or email between the paediatric and adult rheumatology team (and documented in a written communication); one before and one after the transfer. Copies of written communications are to be made available to YP and families. Online supplementary table contains suggested guidelines regarding the content and format of communications at different stages of transitional care.

(4) Individual transition processes and progress should be carefully documented in the medical records and planned with YP and their families.

Documentation should support the YP engagement and selfmanagement skills, resilience and readiness for transfer. ${ }^{69-73}$ This documentation should be tailored to local services, shared with the YP and contribute to the medical summary. The inclusion of sensitive or confidential information (eg, abortion, mental health problems) should be discussed with the YP. Ideally, there is a specific written individual transition plan, ${ }^{26}$ which can be derived from a transition plan or passport example, such as http:// www.uhs.nhs.uk/Media/Controlleddocuments/Patientinformation/ Childhealth/ReadySteadyGo/Ready-Steady-Go-Transition-plan. pdf. ${ }^{21}$ As a minimum, the existence of a transitional care process has to be documented in the medical records. Additional resources are listed in Supplementary material.

(5) Every rheumatology service and clinical network-paediatric and adult-must have a written, agreed and regularly updated transition policy.

Policies and protocols should be agreed with all major stakeholders, including YP, families and all healthcare professionals and as equal partners; ${ }^{27} 3335$ it is important to stress the need to include all specialists (and not just in rheumatology) and primary care physician(s) who are involved in the clinical care of YP with jRMD ${ }^{28}$ Hospital or institutional managers will have to agree to these policies to facilitate appropriate resources to support their implementation within the clinical departments. As a minimum, there must be a transition policy and the documents should be updated at least every 5 years. It is acknowledged that there is need for flexibility of the arrangements in transition policy and care pathways at a network level.

(6) There should be clear written description of the MDT involved in transitional care, locally and in the clinical network. The MDT should include a designated transition co-ordinator.

The team for transitional care should reflect the multidisciplinary approach, that is, doctors and other health professionals, such as nurses, physical therapists, psychologists, occupational therapists and youth or social workers. ${ }^{28} 7475$ It is recognised that certain roles within transition are likely to be addressed by different members of the MDT. ${ }^{76}$ In addition, it is acknowledged that the composition of MDTs is variable and that some members may have more than one role. Ideally, there is personal continuity in the health professionals within the MDT providing care. ${ }^{43}$ This provision of roles and services may be shared with other specialist services and not devoted solely to jRMDs. There should be a nominated and identified member of the MDT, who is responsible as transition co-ordinator (essential). This person can be a nurse or other health professional and should liaise between adult and paediatric teams to ensure the co-ordination of care, facilitation of communication and implementation of the transitional care plan including transfer. ${ }^{35}$

(7) Transition services must be YP focused, be developmentally appropriate and address the complexity of YP development.

Components of YP focused care need to include accessibility to specialised healthcare, staff attitudes, communication, medical competency, guideline-driven care, age appropriate environments and youth involvement in healthcare. ${ }^{77}$ Ideally, there should be a care facility that is truly adolescent-friendly staffed by professionals with expertise in adolescent care. The care should be organised to minimise the frequency of appointments and interruption to the daily life of YP. The aim of the consultations with the MDT is to enable YP to take lead role instead of the parent/carer(s), while also supporting the parent/ carer(s) in their changing roles. 437879

YP with jRMDs should have access to peer discussion and support through advisory group(s) and charity networks. Signposting to such groups and networks is the responsibility of the clinic where the YP attends. As a minimum, transitional care services should be led by staff with expertise and training in adolescent and young adult healthcare.

(8) There must be a transfer document.

The format and content of transfer documents should be agreed by paediatric and adult teams and with patient input where possible. The transfer document should include, as a minimum, a medical summary with the diagnosis, any comorbidities, vaccinations, any complications of disease or treatments, the professionals involved in care, current and 
previous treatments (with reasons for changing treatments and any adverse events). Ideally, it should also include: (i) psychosocial aspects and educational/vocational status at the time of transfer and (ii) a report on self-management skills, to include readiness for transfer and procedural pain management strategies (eg, for joint injections with or without general anaesthesia). ${ }^{80}$

This transfer document may also include contributions from members of the MDT as appropriate and if relevant. Any confidential information or sensitive information to be included in the transfer document should be discussed with the YP; if needed, this should be included in a separate letter to the adult rheumatologist and be written ahead of the first consultation with adult rheumatology. Copies of the transfer document should be available to YP themselves in an easy read format if appropriate, and to all healthcare providers, including primary care, involved in the young person's care. ${ }^{81}$

(9) Healthcare teams involved in transition and adolescent-young adult care must have appropriate training in generic adolescent health and childhood-onset RMD.

All members of the clinical MDT (from adult and paediatric rheumatology) engaged in transition are to have training on adolescent health and the process of transition. ${ }^{46}$ As a minimum, the key training components to be covered are: (1) jRMDs (presentation in childhood, knowledge and approaches to management), (2) adolescence health and the impact on jRMDs, (3) skills and knowledge to address emotional, mental health and social issues, (4) promotion of healthy lifestyle and generic health issues, (5) promotion of self-management and shared decision making, (6) communication skills with YP and their parent/carer(s).

These skills and knowledge can be acquired through different ways of learning (eg, to include clinical experience, e-learning and practical workshops) and should be a component of continuous professional development. There are many courses and e-learning opportunities available, such as the EULAR/PReS On-line Course in Paediatric Rheumatology (http://www.eular. org/edu_online_course_paediatric.cfm), the European Training in Effective Adolescent Care and Health (http://www.unil.ch/ euteach/en/home.html) or the UK Adolescent Health Project (http://www.e-lfh.org.uk). Reciprocal periods of training for members of the adult and paediatric rheumatology teams are advocated (ideal).

(10) There must be secure funding for dedicated resources to provide uninterrupted clinical care and transition services for YP entering adult care.

The following are regarded as essential for transitional care programmes:

(i) The funding and supporting resources for care should be dependent on clinical need and should not be interrupted on sole grounds on the age of the patient. Conversely, the presence or absence of resources should not define the timing of transfer.

(ii) Funding of (biological and other) therapies should continue if clinically indicated irrespective of patient age and transfer to adult care.

(iii) Funding of the paediatric and adult MDTs involved in the transitional care is needed.

(iv) The transition co-ordinator role and administration support for clinical networks must be funded.

(v) The training for the MDT along with continuous professional development support must be funded.

(vi) The importance of adequate administrative support is likely to be a determinant of successful transfer. ${ }^{45} 4881$
(11) There must be a freely accessible electronic-based platform to host the recommendations, standards and resources for transitional care.

An open resource e-platform (essential), such as the EULAR/ PReS website, to host resources to support the transition process, staff training and patient resources, would facilitate setting up of new and further development of existing transition services. All stakeholders must have access to these resources, including YP with jRMDs, their families and healthcare professionals in hospital, primary and community care involved. The resources must be endorsed (essential) by professional bodies such as EULAR/PReS, consumer groups and charities in the respective countries.

(12) Increased evidence-based knowledge and practice is needed to improve outcomes for YP with childhood-onset RMD.

The expert group recognised the need for a greater evidence base to inform best practice, the best metrics for measuring 'success' and 'outcome' of transitional care programmes and the impact of such programmes on YP with jRMDs. ${ }^{7} 37$ The agenda for research needs to include:

(i) the transition programme evaluation as a complex intervention, $^{75}$

(ii) the effectiveness of the transition process ${ }^{35}$ and how this can be measured,

(iii) the timeliness of interventions and validation of readiness tools, ${ }^{69-7382}$

(iv) the outcome measures of transition, ${ }^{37-394183}$

(v) predictors for transition outcomes,

(vi) cohort studies and registries from paediatric rheumatology to extend into adult life,

(vii) an agreed 'core transition dataset' for routine practice in paediatric and adult rheumatology centres to inform and foster future research initiatives, facilitate a standardised approach in transitional care and enable comparative assessment of care across Europe.

\section{Standards and quality indicators}

The expert group concluded that there is a limited evidence base for outcomes of transition and for YP rheumatology services. ${ }^{35}$ The expert group proposed, before the publication of the previous studies, key quality indicators to measure service delivery and to inform the research agenda. Online supplementary table shows a list of standards and the agreed quality indicators.

In 2015, Suris and $\mathrm{Akre}^{80}$ co-ordinated an international consensus on key elements and one indicator of a good transition. In most instances, such consensus underscored items related to co-ordination and communication as basis for good partnership between paediatric and adult providers. Another initiative, developed during our project, obtained a clinical practicebenchmark tool for transition to adult care in the UK through a process of mapping. ${ }^{84}$ There is no single outcome of 'successful' transition and potential indicators need to include clinical parameters (disease activity and status), patient (and family) experience (of care), psychosocial, educational and vocational status, quality of life measures, participation in adult life, engagement and attendance in adult healthcare, adherence to treatment and achievement of young adult developmental tasks. A recent taskforce identified, by Delphi methodology, outcomes of importance. ${ }^{41}$ These included individual outcomes (quality of life, understanding the characteristics of conditions and complications, knowledge of medication, self-management, adherence to medication and understanding health insurance), health services outcomes (attending medical appointments, having a 
medical home and avoidance of unnecessary hospitalisation) and a social outcome (having a social network). Measures need to be valid, reproducible and relevant.

\section{DISCUSSION}

This PReS/EULAR taskforce has developed the first international set of recommendations and standards for transitional care of YP with jRMDs; the aim being to facilitate high-quality models of care for new and existing services, inform strategies for evaluation and define a research agenda. These were produced before the emergence of the 2016 National Institute for Health and Care Excellence (NICE) guidance on Transition in the UK (http://www.nice.org.uk/guidance/ng43) but reassuringly, are consistent NICE recommendations. Our methodology permitted critical appraisal of published models of care and incorporated opinion from a diverse expert specialists group including $\mathrm{YP}^{35}$ Our recommendations and standards set out the 'essential/ minimal' and 'ideal/optimal' components of transitional care and we anticipate that such stratification will be helpful to benchmark services and facilitate implementation and evaluation.

The recommendations focus on transitional rheumatology care, however, they comprise components of high-quality transitional care derived from policy documents, guidelines relating to transitional care and the adolescent health literature. This underlines that, overall, most key elements of transitional care are generic. That is also reflected in the key elements for successful transition, which were published by Suris and Akre ${ }^{80}$ after the recommendations given here were agreed on. Six elements were regarded as being essential by more than $70 \%$ of an international panel, of which two relate to establishing a good partnership between paediatric and adult professionals and the shared responsibility of transitional care. All six essential elements are included in the recommendations given here, which highlight the need for teams to work effectively together and engagement of different care providers within clinical networks. Addressing the challenges of 'joined up' working across paediatric and adult rheumatology and within clinical networks has also been highlighted by others. ${ }^{85}$ Our recommendations, in agreement with other recent taskforces, ${ }^{80} 84$ emphasise the importance of identifying key individuals, the integral role of YP and families, written communication, agreed policy, training and clarity of roles within teams. Therewith, they focus on process areas that are most in need of improvement according to care providers and consumers, such as co-ordination, guidelines, protocols and communication. ${ }^{66}$ It is apparent that a transitional care pathway for YP with jRMDs can be implemented with a motivated healthcare team, the reorganisation of their existing work practice and available resources. ${ }^{29} 31$ The transitional care MDT also needs specific training in adolescent medicine and adequate capacity to enable the transition care co-ordinator role to function. ${ }^{46}{ }^{48}$ Transition is resource consuming. The expert panel stresses the fact that without sufficient funding or reimbursement of the specific interventions, transitional care services cannot become a normal part of healthcare for YP. Funding is needed for specific service provision and to ensure continuity of clinical care and access to medicines after transfer to adult care based on clinical need rather than age of the patient of the provider. There are promising examples in the UK or Germany, where the provision of transitional care services as part of clinical practice has been funded by the government or statutory health insurance companies within defined programmes. $^{32}$ The funding for continuity of clinical care and access to medicines after transfer to adult care has to be addressed and based on clinical need rather than age of the patient of the provider. Given the importance of transition for the many YP who transfer to adult rheumatology, we strongly suggest that transitional care is included in all PReS and EULAR activities to raise awareness, promote access to training and improve skills and knowledge among all adult rheumatology teams.

Quality indicators and outcomes of transitional care are proposed. These transitional care outcomes are similar to most of 10 prioritised outcomes identified by a task force from the Health Care Transition Research Consortium ${ }^{41}$ and may allow researchers to conduct focused evaluations of current processes and more detailed evaluations of interventions.

We acknowledge differences between countries in how transition may be organised within different healthcare systems. ${ }^{66} 86-88$ Our recommendations are intended to be useful, widely applicable and promote transitional care. Although transitional care has received much attention in the child health community, little government attention has been paid to this complex health system issue. An analysis of policy profiles of paediatric-to-adult care transitions in six European countries revealed that four had currently no transition policies or strategies. ${ }^{88}$ The overarching principles seek to promote transferability to different contexts, be compliant with national regulatory guidance and facilitate local teams to work together with responsibility and accountability for services to be suitable for local needs. Our approach is similar to that proposed by others; the Spanish consensus for transition management in patients with $\mathrm{jRMDs}^{89}$ reported a framework with similar recommendations albeit with more practical details suited to the Spanish healthcare system.

Transition is a time-variable process that prepares YP with jRMDs to take responsibilities for their lives and also their health issues. This process is critical in order to facilitate the actual transfer to adult care. Transition is therefore a complex process with many variables involved and the panel required considerable dialogue and indeed compromise to agree the aims, framework and process map to address such complexity. However, as the project evolved and moved forward, harmonisation became apparent and ultimately one round of Delphi was adequate to achieve high agreement.

It is clear that there are many unanswered questions in transitional care. Our recommendations highlight the need for improved evidence base to inform models of care, identify relevant outcome measures and the cost-effectiveness of transitional care programmes as a complex intervention. Much work is yet to be done, but it is important to identify and ultimately deliver 'best' care for YP with jRMDs and their families, to facilitate optimal physical, psychosocial and quality of life outcomes within adulthood.

\footnotetext{
Author affiliations

${ }^{1}$ Newcastle University, Institute of Cellular Medicine (Rheumatology), Newcastle, UK ${ }^{2}$ Children's University hospital Charité, Campus Virchow, SPZ, Berlin, Germany

${ }^{3}$ Epidemiology Unit, German Rheumatism Research Centre, Berlin, Germany

"Paediatric Rheumatology Unit, Hospital Infantil Universitario "Niño Jesús", Madrid,

Spain

${ }^{5}$ Hospital Cínico San Carlos, Instituto de Investigación Sanitaria del Hospital Clínico San Carlos (IDISSC), Madrid, Madrid, Spain

${ }^{6}$ Health Sciences, Universidad Camilo José Cela, Madrid, Madrid, Spain

${ }^{7}$ University of Manchester, Centre for Musculoskeletal Research, Manchester Manchester, UK

${ }^{8}$ Immunology and Infectiology, Erasmus MC—Sophia, Rotterdam, The Netherlands

${ }^{9}$ Karolinska Universitetssjukhuset, Stockholm, Sweden

${ }^{10}$ Department of Paediatrics/Paediatric Rheumatology, Erasmus MC Sophia Children's Hospital Rotterdam, Rotterdam, The Netherlands

${ }^{11}$ Pediatric Immunology, University Hospital Gasthuisberg, Leuven, Belgium

${ }^{12}$ University of Leeds, School of Healthcare, Leeds, UK
} 
${ }^{13}$ University of Sheffield, School of Health and Related Research, Sheffield, Sheffield, UK

${ }^{14}$ Paediatric Rheumatology, Newcastle upon Tyne Hospitals NHS Foundation Trust, Newcastle upon Tyne, Newcastle upon Tyne, UK

${ }^{15}$ London, UK

${ }^{16}$ Pediatria II, Universita degli Studi di Genova Scuola di Scienze Mediche e

Farmaceutiche, Genova, Liguria, Italy

${ }^{17}$ Department of Pediatrics, Semmelweis Egyetem, Budapest, Hungary

${ }^{18}$ Transitionssprechstunde am Dr. von Haunerschen Kinderspital, Ludwig-

Maximilians-Universität München, Munchen, Germany

${ }^{19}$ Gulhane Military Medical Academy, School of Nursing, Ankara, Turkey, Ankara, Turkey

${ }^{20}$ Division of Rheumatology, Department of Internal Medicine, Istanbul University, Istanbul Faculty of Medicine, Istanbul, Turkey

${ }^{21}$ Gulhane Military Medical Faculty, Pediatric Rheumatology Unit, FMF Arthritis Vasculitis and Orphan Disease Research in Pediatric Rheumatology (FAVOR), Etlik, Ankara 06018, Turkey, Ankara, Turkey

${ }^{22}$ Pediatric Rheumatology, Hacettepe University Medical Faculty, Ankara, Turkey

${ }^{23}$ Instituto de Salud Musculoesquelética, Madrid, Spain

Contributors HeEF, KM, DC, LL, JEMD, LC: data abstraction and manuscript preparation; SK, KB, PvP, CW, JW-J, RT, RW, SRS, AM, TC, SS, BF, BE, ED, SO: data abstraction and multidisciplinary panel.

Funding This study was supported by a European League Against Rheumatism grant. The panel is very grateful for the administrative and logistical support from Patrizia Jud.

Competing interests None declared.

Provenance and peer review Not commissioned; externally peer reviewed.

\section{REFERENCES}

1 Blum RW, Garell D, Hodgman CH, et al. Transition from child-centered to adult health-care systems for adolescents with chronic conditions. A position paper of the Society for Adolescent Medicine. J Adolesc Health 1993;14:570-6.

2 Scal P, Horvath K, Garwick A. Preparing for adulthood: health care transition counseling for youth with arthritis. Arthritis Rheum 2009;61:52-7.

3 World Health Organisation. Global Standards for Quality Health Services for Adolescents. Geneva, Switzerland: WHO Press, World Health Organization, 2015.

4 Sawyer SM, Drew S, Yeo MS, et al. Adolescents with a chronic condition: challenges living, challenges treating. Lancet 2007;369:1481-9.

5 Gorter JW, Stewart D, Woodbury-Smith M. Youth in transition: care, health and development. Child Care Health Dev 2011;37:757-63.

6 Park MJ, Adams SH, Irwin CE Jr. Health care services and the transition to young adulthood: challenges and opportunities. Acad Pediatr 2011; 11:115-22.

7 Crowley R, Wolfe I, Lock K, et al. Improving the transition between paediatric and adult healthcare: a systematic review. Arch Dis Child 2011;96:548-53.

8 Nordal E, Zak M, Aalto K, et al. Ongoing disease activity and changing categories in a long-term Nordic cohort study of juvenile idiopathic arthritis. Arthritis Rheum 2011;63:2809-18.

9 Bertilsson L, Andersson-Gäre B, Fasth A, et al. Disease course, outcome, and predictors of outcome in a population-based juvenile chronic arthritis cohort followed for 17 years. J Rheumatol 2013;40:715-24.

10 Selvaag AM, Aulie HA, Lilleby V, et al. Disease progression into adulthood and predictors of long-term active disease in juvenile idiopathic arthritis. Ann Rheum Dis 2016:75:190-5.

11 Vidqvist KL, Malin M, Varjolahti-Lehtinen T, et al. Disease activity of idiopathic juvenile arthritis continues through adolescence despite the use of biologic therapies. Rheumatology (Oxford) 2013;52:1999-2003.

12 Wipff J, Sparsa L, Lohse A, et al. Impact of juvenile idiopathic arthritis on quality of life during transition period at the era of biotherapies. Joint Bone Spine 2016:83:69-74.

13 Sanner H, Gran JT, Sjaastad I, et al. Cumulative organ damage and prognostic factors in juvenile dermatomyositis: a cross-sectional study median 16.8 years after symptom onset. Rheumatology (Oxford) 2009;48:1541-7.

14 Moorthy LN, Peterson MG, Hassett AL, et al. Burden of childhood-onset arthritis. Pediatr Rheumatol Online J 2010;8:20.

15 Díaz-Mendoza AC, Modesto Caballero C, Navarro-Cendejas J. Analysis of employment rate and social status in young adults with childhood-onset rheumatic disease in Catalonia. Pediatr Rheumatol Online J 2015;13:29.

16 Hazel $\mathrm{E}$, Zhang $\mathrm{X}$, Duffy $\mathrm{CM}$, et al. High rates of unsuccessful transfer to adult care among young adults with juvenile idiopathic arthritis. Pediatr Rheumatol Online J 2010;8:2.

17 Hersh A, von Scheven E, Yelin E. Adult outcomes of childhood-onset rheumatic diseases. Nat Rev Rheumatol 2011;7:290-5.

18 Son MB, Sergeyenko $Y$, Guan $H$, et al. Disease activity and transition outcomes in a childhood-onset systemic lupus erythematosus cohort. Lupus 2016;25:1431-9.
19 Tattersall R, McDonagh JE. Transition: a rheumatology perspective. Br J Hosp Med (Lond) 2010:71:315-19.

20 Eleftheriou $D$, Isenberg DA, Wedderburn LR, et al. The coming of age of adolescent rheumatology. Nat Rev Rheumatol 2014;10:187-93.

$21 \mathrm{McD}$ onagh JE, Hackett J, McGee M, et al. The evidence base for transition is bigger than you might think. Arch Dis Child Educ Pract Ed 2015;100: $321-2$

22 Stewart D. Transition to adult services for young people with disabilities: current evidence to guide future research. Dev Med Child Neurol 2009;51(Suppl 4):169-73.

23 McDonagh JE. Young people first, juvenile idiopathic arthritis second: transitional care in rheumatology. Arthritis Rheum 2008;59:1162-70.

24 Rettig P, Athreya BH. Adolescents with chronic disease. Transition to adult health care. Arthritis Care Res 1991;4:174-80.

25 Shaw KL, Southwood TR, McDonagh JE. Growing up and moving on in rheumatology: a multicentre cohort of adolescents with juvenile idiopathic arthritis. Rheumatology (Oxford) 2005;44:806-12.

26 McDonagh JE, Shaw KL, Southwood TR. Growing up and moving on in rheumatology: development and preliminary evaluation of a transitional care programme for a multicentre cohort of adolescents with juvenile idiopathic arthritis. J Child Health Care 2006;10:22-42.

27 Nagra A, McGinnity PM, Davis N, et al. Implementing transition: Ready Steady Go. Arch Dis Child Educ Pract Ed 2015;100:313-20.

28 Tucker LB, Cabral DA. Transition of the adolescent patient with rheumatic disease: issues to consider. Pediatr Clin North Am 2005;52:641-52, viii.

29 Tattersall RS. The MAGICC and practical approach to rheumatology transition. Br J Hosp Med (Lond) 2012;73:552-7.

30 Ammerlaan JW, Scholtus LW, Biilsma HJ, et al. An urge for change: transitional care for young adults with juvenile idiopathic arthritis. Patient Educ Couns 2013:92:127-9.

31 Hilderson D, Westhovens R, Wouters C, et al. Rationale, design and baseline data of a mixed methods study examining the clinical impact of a brief transition programme for young people with juvenile idiopathic arthritis: the DON'T RETARD project. BMJ Open 2013;3:e003591.

32 Minden $\mathrm{K}$, Niewerth $\mathrm{M}$, Müther $\mathrm{S}$. [Berlin transition program: from adolescents to adults in rheumatology treatment]. Z Rheumatol 2014;73:526-31.

33 Jensen PT, Karnes J, Jones K, et al. Quantitative evaluation of a pediatric rheumatology transition program. Pediatr Rheumatol Online I 2015;13:17.

34 Stringer E, Scott R, Mosher D, et al. Evaluation of a rheumatology transition clinic. Pediatr Rheumatol Online J 2015:13:22.

35 Clemente D, León L, Foster H, et al. Systematic review and critical appraisal of transitional care programmes in rheumatology. Semin Arthritis Rheum Published Online First: 9 Jun 2016. doi: 10.1016/j.semarthrit.2016.06.003

36 Hersh A. Growing up and moving on-transition of care for patients with childhood-onset rheumatic disease. J Rheumatol 2014:41:829-31.

37 Prior $\mathrm{M}$, McManus $\mathrm{M}$, White $\mathrm{P}$, et al. Measuring the "triple aim" in transition care: a systematic review. Pediatrics 2014;134:e1648-1661.

38 Davis AM, Brown RF, Taylor JL, et al. Transition care for children with special health care needs. Pediatrics 2014;134:900-8.

39 Scal P. Improving health care transition services: just grow up, will you please. JAMA Pediatr 2016:170:197-9.

40 Castrejón I. [Transitional care programs for patients with rheumatic diseases: review of the literature]. Reumatol Clin 2012;8:20-6.

41 Fair $\mathrm{C}$, Cuttance J, Sharma $\mathrm{N}$, et al. International and interdisciplinary identification of health care transition outcomes. JAMA Pediatr 2016;170:205-11.

42 Reiss J, Gibson R. Health care transition: destinations unknown. Pediatrics 2002;110(6 Pt 2):1307-14

43 Shaw KL, Southwood TR, McDonagh JE. Transitional care for adolescents with juvenile idiopathic arthritis: a Delphi study. Rheumatology (Oxford) 2004:43:1000-6.

44 Shaw KL, Southwood TR, McDonagh JE, et al. User perspectives of transitional care for adolescents with juvenile idiopathic arthritis. Rheumatology (Oxford) 2004:43:770-8

45 Robertson LP, McDonagh JE, Southwood TR, et al., British Society of Paediatric and Adolescent Rheumatology. Growing up and moving on. A multicentre UK audit of the transfer of adolescents with juvenile idiopathic arthritis from paediatric to adult centred care. Ann Rheum Dis 2006;65:74-80.

$46 \mathrm{McD}$ nagh JE, Minnaar $\mathrm{G}$, Kelly $\mathrm{K}$, et al. Unmet education and training needs in adolescent health of health professionals in a UK children's hospital. Acta Paediatr 2006:95:715-19.

47 Ostlie IL, Dale O, Möller A. From childhood to adult life with juvenile idiopathic arthritis ( JIA): a pilot study. Disabil Rehabil 2007;29:445-52.

48 Chira P, Ronis T, Ardoin S, et al. Transitioning youth with rheumatic conditions: perspectives of pediatric rheumatology providers in the United States and Canada. J Rheumatol 2014;41:768-79.

49 World Health Organization. The second decade: improving adolescent health and development. Geneva: World Health Organization, 2001. 
50 Sawyer SM, Afifi RA, Bearinger $\mathrm{LH}$, et al. Adolescence: a foundation for future health. Lancet 2012;379:1630-40.

51 American Academy of Pediatrics, American Academy of Family Physicians, American College of Physicians-American Society of Internal Medicine. A consensus statement on health care transitions for young adults with special health care needs. Pediatrics 2002;110(6 Pt 2):1304-6.

52 Cooley WC, Sagerman PJ, American Academy of Pediatrics, American Academy of Family Physicians, American College of Physicians, et al. Supporting the health care transition from adolescence to adulthood in the medical home. Pediatrics 2011;128:182-200

53 Rosen DS, Blum RW, Britto M, et al. Transition to adult health care for adolescents and young adults with chronic conditions: position paper of the Society for Adolescent Medicine. J Adolesc Health 2003:33:309-11.

54 Society for Adolescent Medicine. Access to health care for adolescents and young adults. J Adolesc Health 2004; 35:342-4.

55 English A, Park MJ, Shafer MA, et al. Health care reform and adolescents: an agenda for the lifespan: a position paper of the Society for Adolescent Medicine. J Adolesc Health 2009;45:310-15.

56 Transition to adult care for youth with special health care needs. Paediatr Child Health 2007;12:785-93.

57 The Royal Australasian College of Physicians. Transition of Young People with Complex and Chronic Disability Needs from Paediatric to Adult Health Services. 2014. https://www.racp.edu.au/ (accessed 27 Oct 2016).

58 World Health Organization. Quality Assessment Guidebook: a guide to assessing health services for adolescent clients. 2009.

59 Organisation WH. Making health services adolescent friendly: developing national quality standards for adolescent friendly health services. 2012. ISBN: 978924150 3594

60 van der Heijde D, Aletaha D, Carmona L, et al. 2014 Update of the EULAR standardised operating procedures for EULAR-endorsed recommendations. Ann Rheum Dis 2015;74:8-13.

61 Goldenring JM, Rosen DS. Getting into adolescent heads: an essential update. Contemp Pediatr 2004;21:64-90.

62 Klein DA, Goldenring JM, Adelman WP. HEEADSSS 3.0: the psychosocial interview for adolescents updated for a new century fueled by media. Contemp Pediatr 2014;31:16-28.

63 McDonagh JE, Southwood TR, Shaw KL. The impact of a coordinated transitional care programme on adolescents with juvenile idiopathic arthritis. Rheumatology (Oxford) 2007:46:161-8.

64 McManus M, White P, Pirtle R, et al. Incorporating the six core elements of health care transition into a Medicaid managed care plan: lessons learned from a pilot project. J Pediatr Nurs 2015;30:700-13.

65 Steinbeck K, Towns S, Bennett D. Adolescent and young adult medicine is a special and specific area of medical practice. J Paediatr Child Health 2014;50:427-31.

66 Sonneveld HM, Strating MM, van Staa AL, et al. Gaps in transitional care: what are the perceptions of adolescents, parents and providers? Child Care Health Dev 2013;39:69-80.

67 van Pelt PA, Drossaert $\mathrm{CH}$, Kruize AA, et al. Use and perceived relevance of health-related Internet sites and online contact with peers among young people with juvenile idiopathic arthritis. Rheumatology (Oxford) 2015:54:1833-41.

68 Rutishauser C, Sawyer SM, Ambresin AE. Transition of young people with chronic conditions: a cross-sectional study of patient perceptions before and after transfer from pediatric to adult health care. Eur J Pediatr 2014;173:1067-74.

69 Klassen AF, Grant C, Barr R, et al. Development and validation of a generic scale for use in transition programmes to measure self-management skills in adolescents with chronic health conditions: the TRANSITION-Q. Child Care Health Dev 2015:41:547-58
70 Schwartz LA, Daniel LC, Brumley LD, et al. Measures of readiness to transition to adult health care for youth with chronic physical health conditions: a systematic review and recommendations for measurement testing and development. J Pediatr Psychol 2014;39:588-601.

71 Zhang LF, Ho JS, Kennedy SE. A systematic review of the psychometric properties of transition readiness assessment tools in adolescents with chronic disease. BMC Pediatr 2014;14:4

72 Stinson J, Kohut SA, Spiegel L, et al. A systematic review of transition readiness and transfer satisfaction measures for adolescents with chronic illness. Int I Adolesc Med Health 2014;26:159-74.

73 Moynihan M, Saewyc E, Whitehouse $S$, et al. Assessing readiness for transition from paediatric to adult health care: revision and psychometric evaluation of the Am I ON TRAC for Adult Care questionnaire. J Adv Nurs 2015;71:1324-35.

74 Cramm JM, Strating MM, Nieboer AP. The role of team climate in improving the quality of chronic care delivery: a longitudinal study among professionals working with chronically ill adolescents in transitional care programmes. BMJ Open 2014;4: e005369.

75 van Staa A, Sattoe JN, Strating MM. Experiences with and outcomes of two interventions to maximize engagement of chronically ill adolescents during hospital consultations: a mixed methods study. J Pediatr Nurs 2015;30:757-75.

76 Woolf AD, European Union of Medical Specialists Section of Rheumatology/ European Board of R. Healthcare services for those with musculoskeletal conditions: a rheumatology service. Recommendations of the European Union of Medical Specialists Section of Rheumatology/European Board of Rheumatology 2006. Ann Rheum Dis 2007;66:293-301.

77 Ambresin AE, Bennett K, Patton GC, et al. Assessment of youth-friendly health care: a systematic review of indicators drawn from young people's perspectives. J Adolesc Health 2013:52:670-81.

78 Reid GJ, Irvine MJ, McCrindle BW, et al. Prevalence and correlates of successful transfer from pediatric to adult health care among a cohort of young adults with complex congenital heart defects. Pediatrics 2004;113(Pt 1):e197-205.

79 Kieckhefer GM, Trahms CM. Supporting development of children with chronic conditions: from compliance toward shared management. Pediatr Nurs 2000;26:354-63.

80 Suris JC, Akre C. Key elements for, and indicators of, a successful transition: an international Delphi study. J Adolesc Health 2015;56:612-18.

81 Chanchlani N, McGee M, McDonagh JE. Informational continuity is integral for successful transition of adolescents to adult care. J Rheumatol 2015;42:901-2.

82 Schwartz LA, Tuchman LK, Hobbie WL, et al. A social-ecological model of readiness for transition to adult-oriented care for adolescents and young adults with chronic health conditions. Child Care Health Dev 2011:37:883-95.

$83 \mathrm{McDonagh}$ JE, Kelly DA. The challenges and opportunities for transitional care research. Pediatr Transplant 2010;14:688-700.

84 Aldiss $\mathrm{S}$, Ellis J, Cass $\mathrm{H}$, et al. Transition from child to adult care: 'It's Not a One-Off Event': development of benchmarks to improve the experience. J Pediatr Nurs 2015:30:638-47.

85 Cruikshank M, Foster HE, Stewart J, et al. Transitional care in clinical networks for young people with juvenile idiopathic arthritis: current situation and challenges. Clin Rheumatol 2016;35:893-9.

86 OECD. Health at a glance: Europe 2012. OECD Publishing, 2012.

87 Wolfe I, Thompson M, Gill P, et al. Health services for children in Western Europe. Lancet 2013;381:1224-34.

88 Hepburn CM, Cohen E, Bhawra J, et al. Health system strategies supporting transition to adult care. Arch Dis Child 2015;100:559-64.

89 Calvo I, Antón J, Bustabad S, et al. Consensus of the Spanish society of pediatric rheumatology for transition management from pediatric to adult care in rheumatic patients with childhood onset. Rheumatol Int 2015:35:1615-24. 
Correction: EULAR/PreS standards and recommendations for the transitional care of young people with juvenile-onset rheumatic diseases

Foster HE, Minden K, Clemente D, et al. EULAR/PreS standards and recommendations for the transitional care of young people with juvenile-onset rheumatic diseases. Ann of Rheum Dis 2017;76:639-46. doi:10.1136/annrheumdis-2016-210112.

The author's name, Erkan Demirkaya, has been corrected.

(c) Article author(s) (or their employer(s) unless otherwise stated in the text of the article) 2018. All rights reserved. No commercial use is permitted unless otherwise expressly granted.

Ann Rheum Dis 2018;77:960. doi:10.1136/annrheumdis-2016-210112corr1

D) Check for updates 